\title{
Short-term outcomes of a single center: Laparoscopic resection of colorectal disease
}

\author{
Osman Civil, ๑ Murat Burç Yazıcıoğlu, @ Abdullah Güneş \\ Department of General Surger, University of Health Sciences Derince Training and Research Hospital, Kocaeli, Turkey
}

\begin{abstract}
Introduction: Laparoscopic colorectal surgery can be performed safely with a low complication rate, short hospital stay, and adequate surgical resection and lymph node dissection. However, it is not accepted as the gold standard in colorectal surgery yet. The objective of this study was to discuss the short-term results of laparoscopic surgical resections for colorectal cancer in the context of the literature.

Materials and Methods: Forty-two patients who underwent laparoscopic colorectal surgery for a malignant etiology between January 2014 and January 2018 were included in the study. The pPatients were evaluated in terms of demographic features, histopathological characteristics of the tumor, type of surgery, and early postoperative complications.

Results: The mean age of the patients was 58.9 years; $36.6 \%$ had a T3 status, while $53.7 \%$ had a diagnosis of N0 stage. There was a median of 14 dissected lymph nodes. Negative surgical margins were obtained in all patients. The mean postoperative hospital stay was 6 days (range: 3-28) days). Postoperative early complications were observed in only $9(21.4 \%)$ patients and $2(4.8 \%)$ patients died in the early postoperative period.

Conclusion: Laparoscopic colorectal surgery can be performed safely with a low complication rate, short hospital stay, sufficient surgical resection, and appropriate lymph node dissection.

Keywords: Colon resection; colorectal surgery; laparoscopy.
\end{abstract}

\section{Introduction}

Laparoscopic colectomy was first described by Jacobs and coworkers in 1991, ${ }^{[1]}$ however application of laparoscopic surgery to colorectal cancer (CRC) treatment took more time than its application to other surgical procedures. The advantages of laparoscopy have been compared and shown in literature with traditional treatment in terms of cosmesis, pain control, bowel function, postoperative morbidity, hospital stay. But the technical difficulties, long learning curve, fear of tumor seeding are the reasons of why laparoscopic surgery is not considered as gold standard in colorectal surgery. ${ }^{[2-8]}$ Recently, no significant difference between open and laparoscopic colorectal surgery in terms of tumor recurrence, distant metastasis rate, overall and disease-free survival is reported. ${ }^{[9]}$ Although it is interpreted as "hand-assisted surgery" by some surgeons due to the incision made to remove the specimen, it is becoming an acceptable alternative procedure to open surgery. ${ }^{[10]}$ Today, laparoscopic colorectal surgery is being widely used in colorectal surgery clinics 
and surgeons who have completed their training in advanced laparoscopic surgery. The aim of our study was to report our findings of laparoscopically operated cases and to discuss with the current literature.

\section{Materials and Methods}

Data of patients who underwent laparoscopic colorectal surgery at S.B.U Derince Training and Research Hospital, Department of General Surgery between January 2014 and January 2018, were included in this study. The files were scanned retrospectively. Demographic characteristics, diagnoses, tumor localization, diameter and stage of tumor, type and duration of operation, number of dissected lymph nodes, length of hospital stay and complications were recorded. Open surgery, emergency cases, and the cases returned to open surgery were excluded from the study. All patients were previously informed about procedure and potential surgical complications and written informed consent was obtained. Patients were operated by the same surgical team with prophylaxis of deep vein thrombosis. Pneumoperitoneum was made to form a pressure of about 12-14 mmHg with carbon dioxide gas. The number and location of the trocar were changed according to the procedure as described in the literature. ${ }^{[1]}$ A mini-laparotomy incision was made approximately 4-5 $\mathrm{cm}$ above the umbilicus for right colon and a $4-5 \mathrm{~cm}$ pfannenstiel incision was made for left colon or rectum operations. The specimen was taken out from these incisions after a wound protector was placed (Alexis ${ }^{\circledR} \mathrm{O}^{\mathrm{TM}}$ Retractor. Applied Medical Resources Corporation, Rancho Santa Margarita, CA, USA). In right colectomy, ileal limb and distal transverse colon were taken out of the abdomen and the anastomosis was completed with 2 flat cutterclosing steppes without reinforcing Lambert sutures. In left colon, the anvil was placed into the proximal limb of the colon and the anastomosis was performed internally. In the case of abdominoperineal resection (APR), the specimen was taken out from the anal tract. High vessel ligation and splenic flexure mobilization were performed in all cases as a standard procedure in the left colon and rectum tumors.

\section{Statistical Analysis}

Data were analyzed using Statistical Package for Social Sciences for Windows version 21.0 (SPSS Inc; Chicago, IL, USA). Parametric data was given as mean \pm standard deviation, and nonparametric data as median with range (minimum-maximum).

\section{Results}

A total of 42 patients were included in the study. Of these, $23(54.8 \%)$ were male and 19 (45.2\%) were female and the mean age was 58.9. According to the American Society of Anesthesiologists (ASA) score, eight (19.0\%) cases were ASA 1, 27 cases (64.3\%) were ASA 2, and 7 (16.7\%) cases were ASA 3. Preoperative complaints of patients were as follow; $11(26.2 \%)$ patients had abdominal pain, 16 (38.1\%) patients had rectal bleeding, and 6 (14.3\%) patients had constipation. Nine of all (21.4\%) were diagnosed while screening of other reasons. Twelve (28.6\%) patients had a history of previous abdominal operation. Thirty-three (31.0\%) patients had hypertension, 7 (16.7\%) patients had diabetes mellitus (DM), 3 (7.1\%) patients had coronary artery disease (CAD), 4 (9.5\%) patients had chronic obstructive pulmonary disease (COPD), 4 (9.5\%) patients had malignancy, $1(2.4 \%)$ patient had chronic renal failure (CRF), and $3(7.1 \%)$ patients had congestive heart failure (CHF). Eleven (26.2\%) patients have habitual smoking. Tumor localizations were as follows; 14 (33.3) in rectum, 11 (26.2\%) in rectosigmoid, 4 (9.5\%) in sigmoid, $1(2.4 \%)$ in transvers colon, $3(7.1 \%)$ in hepatic flexure, 3 $(7.1 \%)$ in ascending colon, and $6(14.3 \%)$ in cecum. The mean duration of hospital stay was 6 days (range, 3-28) (Table 1).

Three (7.1\%) patients had abdominoperineal resection (APR), $22(52.4 \%)$ patients had low anterior resection (LAR), 4 (9.5\%) patients had anterior resection, 1 (26.2\%) patient had extended right hemicolectomy, 11 (26.2\%) had right colectomy and one (2.4\%) patient had subtotal colectomy (Table 2).

Histopathologic results are shown in Table 3. According to the TNM $(\mathrm{n}=41)$ staging, four $(9.8 \%)$ cases were stage 0 , seven (17.1\%) were stage $1,10(24.4 \%)$ were stage 2,15 (36.6\%) were stage 3 and 4 (12.2\%) were stage 4. Pathology results of one patient could not be reached. Tumor differentiation of was reported for 38 cases. Two (4.8\%) of the cases had poorly differentiated tumors, while 28 (66.7\%) cases had moderate, and $8(19.0 \%)$ cases were well-differentiated tumors. A total of 12 patients (30\%) had vascular invasion and 14 cases (35.5\%) had perineural invasion $(n=40)$. There was a mean of 14.4 lymph nodes identified in the specimens. The mean operative time was 133.2 minutes. The mean amount of bleeding during operation was $100 \mathrm{~mL}$. Our complication rates were summarized in Table 1. Diversion ileostomy was performed in 18 (42.9\%) cases. Four trocar were used in seven $(16.7 \%)$ cases and 
Table 1. Demographics and preoperative characteristics of patients $(n=42)$

Age

$58.9 \pm 13.8$

Male

$23(54.8)$

Female

$19(45.2)$

Preoperative compliance

Abdominal pain

$11(26.2)$

Rectal bleeding

$16(38.1)$

6 (14.3)

9 (21.4)

Check-up

Localization of the lesion

Cecum

$6(14.3)$

Ascending colon

$3(7.1)$

Hepatic flexure

Transverse kolon

Sigmoid colon

Rectosigmoid

Rectum

Liver metastasis

Lung metastasis

Neoadjuvant radiotherapy

Postoperative Hospital stay

Mortality

Abdominal operation

ASA score

1

2

3

Comormidities

Hypertension

Diabetes mellitus

Coronary artery disease

Chronic obstructive pulmonary

disease

Malignancy

Chronic renal failure

Congestive heart failure

Smoking

Operation time

Perop bleeding

Complications

Abdominal abscess

Anastomotic leakage $(\mathrm{AL})$

Superficial Surgical site infection

lleus

Urine retention

Urinary incontinence

Bleeding

lleostomy
Table 2. Types of laparoscopic performed procedures

Laparoscopic procedure

Number of patients

\begin{tabular}{lcc}
\cline { 2 - 3 } & $\mathbf{n}$ & $\%$ \\
\hline Abdominoperineal resection & 3 & 7.1 \\
Low anterior resection & 22 & 52.4 \\
Anterior resection & 4 & 9.5 \\
Extended right resection & 1 & 2.4
\end{tabular}

Table 3. Histopathologic characteristics of patients

with colorectal cancer $(n=30)$

$\begin{array}{lc}\text { TNM stage } & (\mathrm{n}=41) \\ 0 & 4(9.8)^{*} \\ 1 & 7(17.1) \\ 2 & 10(24.4) \\ 3 & 15(36.6) \\ 4 & 5(12.2) \\ \text { T stage } & (\mathrm{n}=41) \\ 0 & 4(9.8) \\ 1 & 1(2.4) \\ 2 & 6(14.6) \\ 3 & 26(63.4) \\ 4 & 4(9.8) \\ \text { N stage } & (\mathrm{n}=41) \\ 0 & 22(53.7) \\ 1 & 12(29.3) \\ 2 & 7(17.1) \\ \text { Number of retrieved lymph } & \\ \text { nodes (median) } & 14.4 \pm 8.2 \\ \text { Lymphovascular invasion } & 12(30.0)(\mathrm{n}=40) \\ \text { Perineural invasion } & 14(35.0)(\mathrm{n}=40) \\ \text { Metastatic } & 5(12.2) \\ \text { Total } & \\ \text { Right hemicolectomy } & 11(26.2) \\ \text { Tumor differentiation } & (\mathrm{n}=38) \\ \text { Poor } & 2(4.8) \\ \text { Modorate } & 28(66.7) \\ \text { Well } & 8(19.0) \\ \end{array}$

*Complete response to neoadjuan-chemotherapy.
$3(7.1)$

$2(4.8)$

$1(2.4)$

$1(2.4)$

$1(2.4)$

$1(2.4)$

18 (42.9)
5 trocar was used in $35(83.3 \%)$ cases. Four (9.5\%) patients had liver and 1 (2.4\%) had lung metastases. Eight (57.1\%) patients with rectal tumor were treated with longterm neoadjuvant therapy and complete remission was achieved in four of them. Mortality was seen in 2 cases $(4.8 \%)$ (Table 1). 


\section{Discussion}

Colorectal cancer (CRC) is the third leading cancer type among all cancers and also one of the important causes of cancer-related deaths in both genders. Laparoscopy is being widely used in the treatment of both malign and benign colorectal diseases in many surgical centers where were advanced in laparoscopic procedures. ${ }^{[7,12,13]}$ Previous research has demonstrated its advantages when compared with open surgery, such as short hospital stay, greater satisfaction with incision cosmesis, oncological equivalence, postoperative recovery time, and cost effectiveness. ${ }^{[9,13-16]}$

The complication rate of laparoscopic colorectal procedures were reported as $1.5-36 \%$ and is not higher than open surgery. ${ }^{[2,17]}$ Our complication rate was $21.4 \%$ and the most common complication in our series was anastomotic leakage (AL) (7.1\%). The etiology of AL is considered as multifactorial. ${ }^{[18]}$ Colorectal leakage rates have been found to vary according to the anastomosis location, with distal colorectal, coloanal and ileoanal leak rates ranging from $1 \%$ to $20 \%$, colocolonic leak rates from $0 \%$ to $2 \%$, ileocolonic leak rates from $0.02 \%$ to $4 \% \cdot{ }^{[18-21]}$ Kwak et al. ${ }^{[22]}$ reported the overall leakage rate was 3.78\% (16/423 patients) and habitual smoking was found to be associated with AL. Kim et al. ${ }^{[23]}$ analyzed risk factors for AL and found that male gender was identified as a risk factor and leakage was 13.2 times higher in men than in women. The other accused factors caused AL which were related to patient and operation are preoperative nutritional status, neoadjuvant therapy, tumor size and stage, post-operative hypoalbuminemia, post-operative diarrhea, number of linear stapler firing, and duration of operation. ${ }^{[18]}$ In our study three AL were seen. Two of three AL patients had histories of neoadjuvant therapy and a long time of habitual smoking. Additionally one of them was male with poor preoperative feeding. One of three AL has also an intra-abdominal abscess which was controlled with percutaneous drainage catheter while leakage was treated with colonic self-expandable metal stent. One AL case was reoperated and Hartmann colostomy was done. The third AL case was a patient who has diversion ileostomy and leakage became a controlled fistula by pelvic drain and then spontaneously closed on $28^{\text {th }}$ days of postoperative period.

In a study conducted by Gilmore et al., ${ }^{[24]}$ the average operation time was reported as 156 minutes, while in our study this time was 133.2 minutes. With the increase in laparoscopic experience, we think that the average operation time will be decreased and, approximately 20-30 cases should be done as break point of this experience. ${ }^{[25]}$

Attaallah et al. ${ }^{[13]}$ reported the average hospitalization stay as 5 days and Masoomi et al. ${ }^{[26]}$ reported the average hospital stay was 5.4 days. In our study, the average hospital stay was 6 (3-28) days. Six days hospital stay is due to long-term follow-up of the patient who has protective ileostomy and leakage. Otherwise, we think hospital stay in our study is compatible with the literature.

There are relative contraindications for laparoscopic colorectal surgery such as major cardiac or pulmonary disease, portal hypertension, coagulopathy, pregnancy, tumor obstruction and/or perforation, as well as T4 tumors. ${ }^{[20]}$ However, Bellio et al. ${ }^{[27]}$ reported that T4 colon cancers are no longer being an absolute contraindication to laparoscopic resection. In our study, 4 (9.8\%) patients had T4 disease and underwent laparoscopic resection.

The most important criteria accepted for survival is the sufficient number of dissected lymph nodes, the clearance of the borders and radial margins from the tumor. Evaluation of at least $12 \mathrm{LN}$ after colorectal resection has been accepted in clinical guidelines. ${ }^{[28]}$ Attaallah et al., ${ }^{[13]}$ reported the mean number of lymph nodes in the final pathology specimens as 17. Our mean number of lymph nodes in the final pathology specimens was 14.4 , and all the resection specimens had tumor-free surgical margins but our follow-up period and study size are low to interpret oncologic outcome.

The mortality rates ranged from $2.5 \%$ to $5.9 \%$ for traditional technique. ${ }^{[29-31]}$ It was shown that laparoscopic colorectal surgery was not associated with a higher rate of postoperative mortality. ${ }^{[30,32]}$ In a meta-analysis Gouvas et al. ${ }^{[31]}$ reported a mortality rate between $\% 0$ to $\% 8.3$ for conversion of a laparoscopic colorectal procedure to open surgery, and $\% 0$ to $\% 15.2$ for the laparoscopic surgery. Anastomotic dehiscence following colorectal surgery represented the first etiology of deaths, accounting for $20 \%$ to $33 \%$ of all of the deaths. ${ }^{[33]}$ Alves et al., ${ }^{[30]}$ reported that most of the postoperative deaths were caused by postoperative medical complications, including cardiorespiratory and cerebrovascular complications, and they found 6 independent risk factors of postoperative morbidity as four factors depends on the patient's characteristics (age older than 70 years, neurologic comorbidity, cardiorespiratory comorbidity, hypoalbuminemia) and 2 factors depends 
on the surgical procedure (long duration of operation and fecal contamination). In our study two patients died. One was died because of cardiorespiratory comorbidity in the post-operative 5th day in intensive care unit. The other was died from anastomotic leakage and bleeding. Though we did not made any multivariate logistic regression analyses to determine the independent risk factors of postoperative morbidity, the ratio was compatible with literature.

Major limitations of our study are the small sample size, short follow-up period and the retrospective design of the study. In addition, the outcomes of this study group were not compared with that of patients with open surgery.

As a conclusion, laparoscopic colorectal surgery is not a gold standard procedure but it is becoming more popular among surgeons day by day. It can be performed safely, with low complication rates, short hospital stay, sufficient extent of surgical resection, and sufficient lymph node dissection. Our short-term results were similar with the literature in terms of complication rates and other data.

\section{Disclosures}

Peer-review: Externally peer-reviewed.

Conflict of Interest: None declared.

\section{References}

1. Jacobs M, Verdeja JC, Goldstein HS. Minimally invasive coIon resection (laparoscopic colectomy). Surg Laparosc Endosc 1991;1:144-50.

2. Clinical Outcomes of Surgical Therapy Study Group, Nelson $H$, Sargent DJ, Wieand HS, Fleshman J, Anvari M, Stryker SJ, et al. A comparison of laparoscopically assisted and open colectomy for colon cancer. N Engl J Med 2004;350:2050-9.

3. Guillou PJ, Quirke P, Thorpe H, Walker J, Jayne DG, Smith AM, et al. Short-term endpoints of conventional versus laparoscopic-assisted surgery in patients with colorectal cancer (MRC CLASICC trial): multicentre, randomised controlled trial. Lancet 2005;365:1718-26. [CrossRef]

4. Ringressi MN, Boni L, Freschi G, Scaringi S, Indennitate G, Bartolini I, et al. Comparing laparoscopic surgery with open surgery for long-term outcomes in patientswith stage I to III colon cancer. Surg Oncol 2018;27:115-22. [CrossRef]

5. Berends FJ, Kazemier G, Bonjer HJ, Lange JF. Subcutaneous metastases after laparoscopic colectomy. Lancet 1994;344:58. [CrossRef]

6. Vukasin P, Ortega AE, Greene FL, Steele GD, Simons AJ, Anthone GJ, et al. Wound recurrence following laparoscopic colon cancer resection. Results of the American Society of Colon and Rectal Surgeons Laparoscopic Registry. Dis Colon
Rectum 1996;39:S20-3. [CrossRef]

7. Yılmaz EM, Cartı EB, Kandemir A. Our Experience of Laparoscopic Colorectal Surgery: Short Term Outcomes. Turk J Colorectal Dis 2016;26:108-12. [CrossRef]

8. Lee SW. Laparoscopic procedures for colon and rectal cancer surgery. Clin Colon Rectal Surg 2009;22:218-24. [CrossRef]

9. Pascual M, Salvans S, Pera M. Laparoscopic colorectal surgery: Current status and implementation of the latest technological innovations. World J Gastroenterol 2016;22:70417. [CrossRef]

10. Ivatury SJ, Bostock Rosenzweig IC, Holubar SD. Short-term Outcomes After Open and Laparoscopic Colostomy Creation. Dis Colon Rectum 2016;59:543-50. [CrossRef]

11. Gezen C, Altuntas YE, Kement M, Vural S, Civil O, Okkabaz N, et al. Complete versus partial mobilization of splenic flexure during laparoscopic low anterior resection for rectal tumors: a comparative study. J Laparoendosc Adv Surg Tech A 2012;22:392-6. [CrossRef]

12. Siegel $R$, Desantis $C$, Jemal A. Colorectal cancer statistics, 2014. CA Cancer J Clin 2014;64:104-17. [CrossRef]

13. Attaallah W, Babayev H, Yardımcı S, Cingi A, Uğurlu MÜ, Günal Ö. Laparoscopic resection for colorectal diseases: short-term outcomes of a single center. Ulus Cerrahi Derg 2016;32:199-202. [CrossRef]

14. Jayne DG, Thorpe HC, Copeland J, Quirke P, Brown JM, Guillou PJ. Five-year follow-up of the Medical Research Council CLASICC trial of laparoscopically assisted versus open surgery for colorectal cancer. Br J Surg 2010;97:1638-45.

15. Biondi A, Grosso G, Mistretta A, Marventano S, Toscano C, Drago $F$, et al. Laparoscopic vs. open approach for colorectal cancer: evolution over time of minimal invasive surgery. BMC Surg 2013;13 Suppl 2:S12. [CrossRef]

16. Simunovic M, Baxter NN, Sutradhar R, Liu N, Cadeddu M, Urbach $D$. Uptake and patient outcomes of laparoscopic colon and rectal cancer surgery in a publicly funded system and following financial incentives. Ann Surg Oncol 2013;20:3740-6.

17. Curet MJ, Putrakul K, Pitcher DE, Josloff RK, Zucker KA. Laparoscopically assisted colon resection for colon carcinoma: perioperative results and long-term outcome. Surg Endosc 2000;14:1062-6. [CrossRef]

18. Sciuto A, Merola G, De Palma GD, Sodo M, Pirozzi F, Bracale $U M$, et al. Predictive factors for anastomotic leakage after laparoscopic colorectal surgery. World J Gastroenterol 2018;24:2247-60. [CrossRef]

19. Crafa F, Smolarek S, Missori G, Shalaby M, Quaresima S, Noviello A, et al. Transanal Inspection and Management of Low Colorectal Anastomosis Performed With a New Technique: the TICRANT Study. Surg Innov 2017;24:483-91.

20. Ito $M$, Sugito $M$, Kobayashi $A$, Nishizawa $Y$, Tsunoda $Y$, Saito $\mathrm{N}$. Relationship between multiple numbers of stapler firings during rectal division and anastomotic leakage after laparoscopic rectal resection. Int J Colorectal Dis 2008;23:703-7.

21. Badawi A. Anastomotic Leak in Laparoscopic Colorectal Surgery: Risk Factors and Prevention. World 2015;8:43-7.

22. Kwak HD, Kim SH, Kang DW, Baek SJ, Kwak JM, Kim J. Risk 
Factors and Oncologic Outcomes of Anastomosis Leakage After Laparoscopic Right Colectomy. Surg Laparosc Endosc Percutan Tech 2017;27:440-4. [CrossRef]

23. Kim SH, Park IJ, Joh YG, Hahn KY. Laparoscopic resection of rectal cancer: a comparison of surgical and oncologic outcomes between extraperitoneal and intraperitoneal disease locations. Dis Colon Rectum 2008;51:844-51. [CrossRef]

24. Gilmore BF, Sun Z, Adam M, Kim J, Ezekian B, Ong C, et al. Hand-Assisted Laparoscopic Versus Standard Laparoscopic Colectomy: Are Outcomesand Operative Time Different? J Gastrointest Surg 2016;20:1854-60. [CrossRef]

25. Stocchi L, Nelson H. Laparoscopic colectomy for colon cancer: trial update. J Surg Oncol 1998;68:255-67. [CrossRef]

26. Masoomi H, Moghadamyeghaneh Z, Mills S, Carmichael JC, Pigazzi A, Stamos MJ. Risk factors for conversion of laparoscopic colorectal surgery to open surgery: does conversion worsen outcome? World J Surg 2015;39:1240-7. [CrossRef]

27. Bellio G, Lo Cicero A, Barbieri V, Tarchi P, Casagranda B, DE Manzini N. Is T4 colon cancer still an absolute contraindication to laparoscopic surgery? Minerva Chir 2017;72:483-90.

28. McDonald JR, Renehan AG, T O'Dwyer S, Haboubi NY. Lymph node harvest in colon and rectal cancer: current consider- ations. World J Gastrointest Surg 2012;4:9-19. [CrossRef]

29. Prystowsky JB, Bordage G, Feinglass JM. Patient outcomes for segmental colon resection according to surgeon's training, certification, and experience. Surgery 2002;132:663-70.

30. Alves A, Panis Y, Mathieu P, Mantion G, Kwiatkowski F, Slim K; Association Française de Chirurgie. Postoperative mortality and morbidity in French patients undergoing colorectal surgery: results of a prospective multicenter study. Arch Surg 2005; 140:278-83. [CrossRef]

31. Gouvas N, Georgiou PA, Agalianos C, Tzovaras G, Tekkis P, Xynos E. Does Conversion to Open of Laparoscopically Attempted Rectal Cancer Cases Affect Short- and Long-Term Outcomes? A Systematic Review and Meta-Analysis. J Laparoendosc Adv Surg Tech A 2018;28:117-26. [CrossRef]

32. Law WL, Lee YM, Choi HK, Seto CL, Ho JW. Laparoscopic and open anterior resection for upper and mid rectal cancer: an evaluationof outcomes. Dis Colon Rectum 2006;49:110815. [CrossRef]

33. Alves A, Panis Y, Trancart D, Regimbeau JM, Pocard M, Valleur $P$. Factors associated with clinically significant anastomotic leakage after large bowel resection: multivariate analysis of 707 patients. World J Surg 2002;26:499-502. [CrossRef] 